\title{
BMJ Open Temporal trends in the prevalence and causes of visual impairment in the South Indian state of Telangana: a population-based cross-sectional study
}

\author{
Srinivas Marmamula, ${ }^{\oplus 1,2,3,4}$ Rohit C Khanna, ${ }^{1,4}$ Shashank Yellapragada, ${ }^{1,2}$ \\ Rajesh Challa, ${ }^{1}$ Javed Mohd, ${ }^{1,2}$ Gullapalli Nageswara Rao ${ }^{1,2}$
}

To cite: Marmamula S, Khanna RC, Yellapragada S, et al. Temporal trends in the prevalence and causes of visual impairment in the South Indian state of Telangana: a population-based crosssectional study. BMJ Open 2019;9:e029114. doi:10.1136/ bmjopen-2019-029114

- Prepublication history for this paper is available online. To view these files, please visit the journal online (http://dx.doi org/10.1136/bmjopen-2019029114).

Received 15 January 2019 Revised 19 June 2019 Accepted 20 June 2019

Check for updates

(c) Author(s) (or their employer(s)) 2019. Re-use permitted under CC BY-NC. No commercial re-use. See rights and permissions. Published by BMJ.

For numbered affiliations see end of article.

Correspondence to Dr Srinivas Marmamula; sri.marmamula@lvpei.org

\section{ABSTRACT}

Objectives To investigate the temporal trends in the prevalence and causes of visual impairment $(\mathrm{VI})$ in South India.

Design Population-based cross-sectional studies conducted during the years 2011-2012 and 2017 using identical study methods and in geographical locations are compared. The L V Prasad Eye Institute established services in Khammam and not in Warangal district after the 2011-2012 study.

Setting Khammam and Warangal districts in Telangana, India.

Participants In total, 5357 participants aged $\geq 40$ years were examined from two districts in the 2011-2012 study and 4923 participants were examined in the 2017 study.

Main outcome measures Age-adjusted and genderadjusted temporal trends in the prevalence and causes of VI. Blindness and moderate VI (MVI) were defined as presenting visual acuity worse than $6 / 60$ and $6 / 18-6 / 60$ in the better eye, respectively. VI included MVI and blindness. Results Nearly 2500 participants were examined in each location in both the 2011-2012 and 2017 studies. In Khammam district, overall VI declined by $2.5 \%$ from $15.5 \%$ to $13.0 \%(p<0.001)$. While there was no significant change in MVI $(p=0.566)$, blindness declined by $3.0 \%$ from $5.4 \%$ to $2.4 \%(p<0.001)$. In Warangal district, the overall $\mathrm{VI}$ remained unchanged $(p=0.60)$. While MVI increased by $3 \%$ from $9.3 \%$ to $12.3 \%(p=0.001)$, blindness declined by $3.5 \%$ from $6.5 \%$ to $3.0 \%(p<0.001)$. While MVI due to cataract increased in both districts, there was a significant decline in MVI due to refractive errors in Khammam. Conclusion There was a significant decline in VI in Khammam district but not in Warangal district. The differential trends in prevalence and causes of VI can be explained by the availability and uptake of eye care services in these two districts.

\section{INTRODUCTION}

Vision loss adversely affects over 253 million people worldwide. ${ }^{1}$ A large proportion of this visual impairment (VI) is avoidable. ${ }^{2}$ Reliable epidemiological data are a prerequisite for the planning and management of eye care services. While national surveys are important

\section{Strengths and limitations of this study}

- A large population-based study design that achieved a good response rate and covered two large districts in the state of Telangana.

- Identical study methods applied at baseline and 5 years later at the same geographical locations.

- Provided insights on temporal trends in prevalence and causes of visual impairment (VI) that can be used for programme planning.

- There are limited data on the change in services providers contributing to differential trends in the prevalence of VI.

to provide the data for policy formulation and resource allocation at the national level, regional studies are equally important due to significant regional variations in the prevalence of vision loss. ${ }^{3-8}$ These regional studies are more important in large and diverse countries such as India, where the differences between the districts even within the same state are significant. The WHO Global Action Plan 2014-2019 highlights the need for compiling regional prevalence data that can be used for planning eye care services to address regional priorities. It also recommends repeat surveys in regions where surveys were conducted previously to assess the trends in the prevalence of VI over a period of time. ${ }^{9}$ Rapid assessments have proven to be invaluable tools in assessing the burden of VI in several countries. ${ }^{10}$ Rapid data collection at relatively low cost, using local resources and repeatable protocols at stipulated intervals to study trends have been the strengths of the rapid assessment methods. ${ }^{10} 11$

Rapid assessment studies, using the Rapid Assessment of Visual Impairment methodology, were first conducted during 2011-2012 using representative samples of the population in the districts of Khammam and Warangal in 


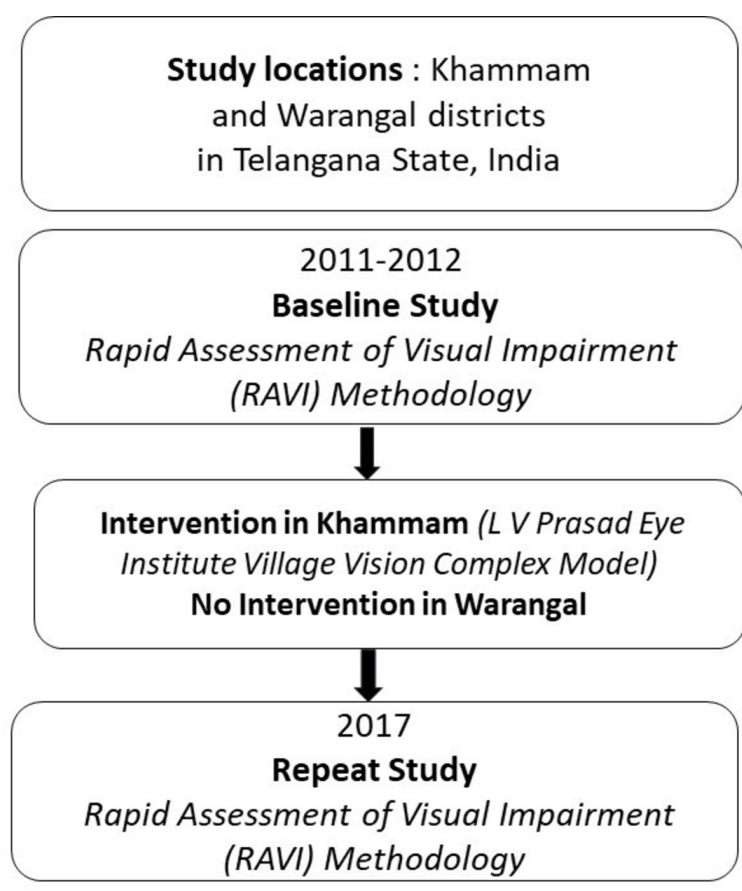

Objectives:

- Prevalence and causes of visual impairment

- Prevalence of spectacles use and coverage

\section{Objectives: \\ - Trends in the prevalence and causes of visual impairment \\ - Temporal trends is spectacles use and coverage}

Figure 1 Schematic diagram showing the study design.

Telangana. ${ }^{4512-15}$ Following these studies, the L V Prasad Eye Institute (LVPEI) set up a network of 1 secondary and 10 primary eye care centres (vision centres) in Khammam district while no new eye care services were initiated in Warangal district. ${ }^{16}$ A repeat study was undertaken in the same geographical locations in these two districts in the year 2017 to assess and compare the temporal trends in the prevalence of VI. The aim of this paper is to present the temporal trends in the prevalence and causes of VI in Khammam and Warangal districts of Telangana state.

\section{MATERIALS AND METHODS}

The study is conducted in accordance with the tenets of the Declaration of Helsinki. Written informed consent was obtained from all the participants.

The baseline study was conducted during 2011-2012 and a repeat study was carried out in the year 2017. The minimum sample size required at each site was 2500 participants based on an expected prevalence of VI of $6 \%$, precision $20 \%$ with $95 \%$ error bound and $10 \%$ non-response rate. A multistage random cluster sampling method was used to select the study participants. The study design is shown in figure 1 . The study areas are shown in figure 2 .

\section{Data collection}

The data collection methods have been described in previous publications. ${ }^{151718}$ In short, a team comprising of a vision technician and a community eye health worker visited the selected clusters to conduct eye examinations. Presenting and pinhole visual acuity (VA) was assessed among all participants in ambient lighting conditions using a standard Snellen chart at a distance of $6 \mathrm{~m}$. Aided VA among spectacle users and unaided VA among non-spectacles users is considered as presenting VA. If the presenting VA was worse than 6/12, then VA was recorded using a multiple pinhole occluder. Presenting near vision was assessed binocularly using the $\mathrm{N}$ notation chart at a fixed distance of $40 \mathrm{~cm}$ for each individual. Near vision was reassessed for subjects with near vision worse than N8 by using near plus lenses in a trial frame appropriate for that age. Torchlight examination and distance direct ophthalmoscopy were done to assess the anterior segment of the eye including the lens status. Identical study protocols were used in both the studies conducted during 2011-12 and 2017. In 2017, in addition to the above mentioned protocols, in the later phase, slit lamp examination and fundus imaging using a non-mydriatic fundus camera (Zeiss Visuscout 100) were done for all the participants.

A questionnaire was used to collect sociodemographic and other information such as education level, current and previous use of spectacles and eye drops, details of surgeries undergone, and perceived barriers to the uptake of eye care services. Subjects with VI and those who needed eye care services were referred to the nearest secondary eye care centre where a comprehensive eye examination, which included a dilated fundus examination was conducted. Services were provided to all the participants at 'no cost' to them. Moderate VI (MVI) was defined as presenting VA worse than 6/18-6/60 and blindness was defined as VA worse than 6/60. VI included MVI and blindness.

In addition to the clinical procedures mentioned above, a validated questionnaire on awareness of common eye conditions and eye donation was administered on a subsample of the enumerated subjects. The Washington Disability Questionnaire (short version) was used to assess 


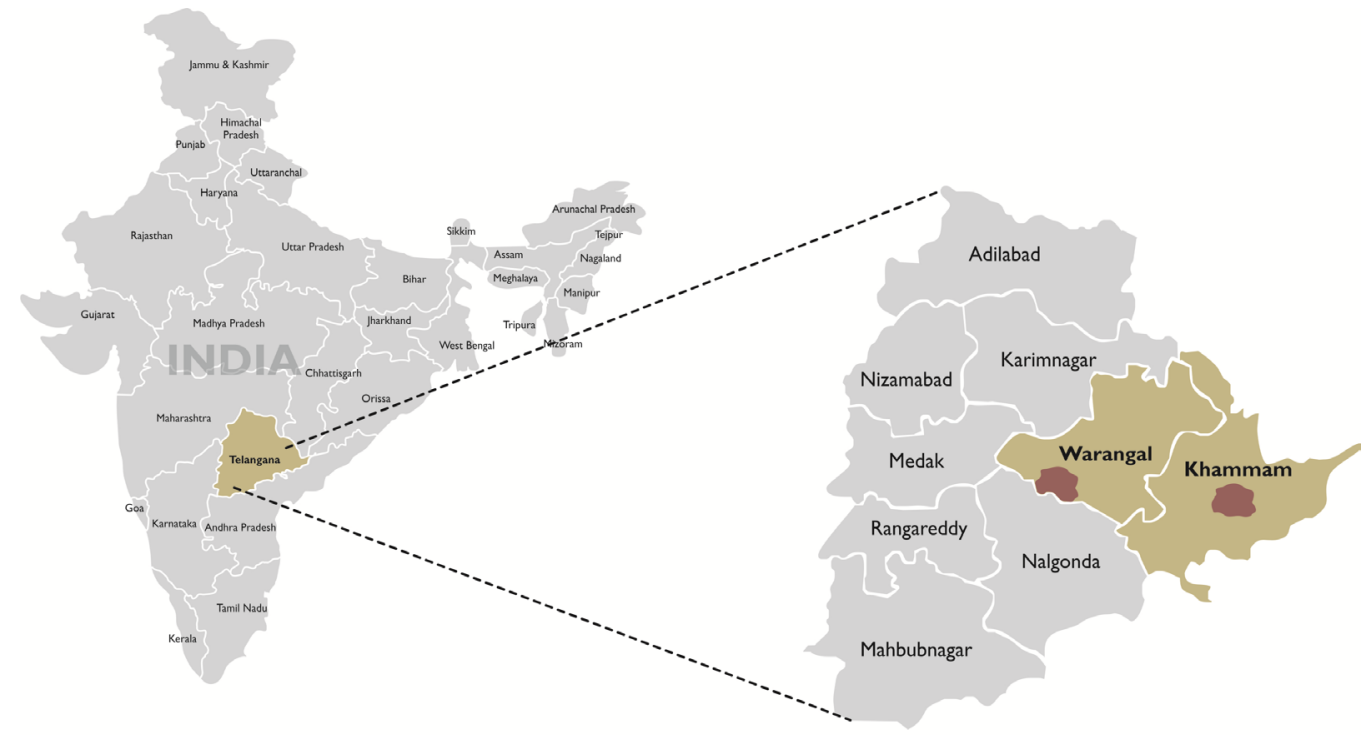

Study Area

Figure 2 Map showing the study locations (Khammam and Warangal).

the self-reported disabilities covering six domainshearing, seeing, cognition, self-care, communication and mobility. ${ }^{19}$ Both questionnaires were administered in the local language (Telugu) by trained field investigators. Both these questionnaires were translated into Telugu and then back translated by bilingual experts before final administration in the field.

\section{Patient and public involvement}

Patients and other members of the public were not involved in the study.

\section{Data management}

Data were initially collected on paper forms and then entered in a database created using Microsoft Access. Data analysis was done using 'Stata Statistical Software' for Windows V.14. All prevalence estimates were adjusted for age and gender distribution of the population and were presented with $95 \%$ CIs. These adjusted prevalence estimates from 2011-2012 and 2017 studies were compared to understand the trends in the prevalence of VI over time. As most rapid assessment studies include participants aged 50 years and older, results for this age group (subsample) are also presented to facilitate comparison with other studies.

\section{RESULTS}

\section{Demographic characteristics}

In 2017, 6000 participants aged $\geq 40$ years were enrolled from 120 study clusters in Khammam and Warangal districts. Of these, 5357 participants were examined (response rate $=89 \%$ ). The characteristics of the 2011-2012 and 2017 participants are shown in table 1. In the 2011-2012 study, 4923 participants were examined of which $2602(52.3 \%)$ were women. The mean age of the participants was 52.0 (SD 11.3 years) years in the 2011-2012 study and 54.1 (SD 11.3 years) years in the 2017 study in Khammam district. The mean age was 52.2 (SD 10.6 years) years in 2011-2012 and 57.0 (SD 12.1 years) years in 2017 study in Warangal. A significantly higher proportion of women were examined in Khammam in 2017 compared with that in the 20112012 study $(\mathrm{p}<0.01)$ whereas the gender proportions were similar in Warangal $(\mathrm{p}=0.2)$. The level of education was comparable in both the locations at both the time intervals.

In comparison to the 2011-2012 study, there was a significant increase in the prevalence of spectacles use for distance vision in Khammam $(\mathrm{p}<0.01)$ but it declined in Warangal district $(\mathrm{p}=0.01)$. Similarly, there was a significant increase in the prevalence of cataract surgery in Khammam $(\mathrm{p}=0.01)$ but it remained stable in Warangal district $(\mathrm{p}=0.58)$.

\section{Trends in the prevalence of VI}

The comparison of prevalence of VI in Khammam and Warangal districts during the 2011-2012 and 2017 studies is shown in figure 3. In Khammam district, the overall prevalence of VI declined from $15.5 \%$ to $13.0 \%$ $(p<0.001)$. While there was no significant change in MVI ( $\mathrm{p}=0.566)$, blindness declined from $5.4 \%$ to $2.4 \%$ $(\mathrm{p}<0.001)$. In Warangal district, the overall prevalence of VI remained unchanged $(\mathrm{p}=0.60)$. While the prevalence of MVI increased from $9.3 \%$ to $12.3 \%(p=0.001)$, blindness declined from $6.5 \%$ to $3.0 \% \quad(\mathrm{p}<0.001)$ (table 2).

\section{Trends in the cause-specific prevalence of VI}

In Khammam, the prevalence of MVI caused due to cataract increased from $1.8 \%$ to $4.2 \%(\mathrm{p}<0.001)$ but 
Table 1 The characteristics of the study participants in the 2011-2012 and 2017 studies (univariable analysis)

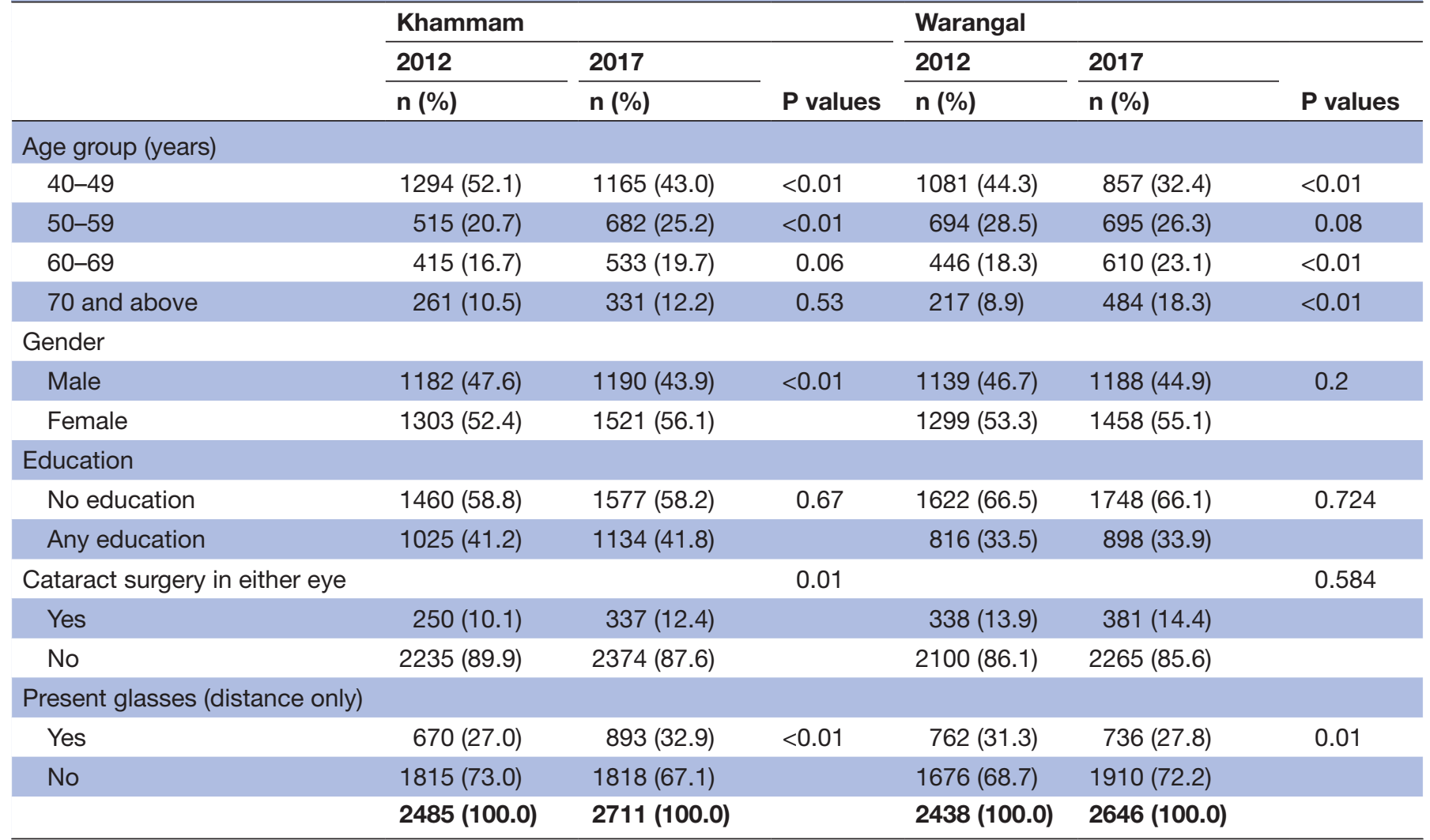

the prevalence of MVI caused due to refractive errors declined from $8.1 \%$ to $5.5 \%(\mathrm{p}<0.001)$. Blindness caused due to cataract and refractive errors showed a significant decline by $2.3 \%(\mathrm{p}<0.001)$ and $0.6 \%(\mathrm{p}=0.008)$, respectively. In Warangal district, the prevalence of MVI caused due to cataract increased from $2.7 \%$ to $5.0 \% \quad(\mathrm{p}<0.001)$ whereas there was no significant change in prevalence of MVI caused due to refractive errors and other causes. As in Khammam, even in Warangal blindness caused due to cataract and refractive errors showed a significant decline by $3.0 \% \quad(<0.001)$ and $0.4 \% \quad(\mathrm{p}<0.001)$, respectively (table 2).

Trends in the prevalence of $\mathbf{V I}$ among $\mathbf{5 0}$ years and older age groups

The comparison of prevalence and causes of VI among those aged 50 years and older in Khammam and Warangal districts during the 2011-2012 and 2017 studies is shown in table 3 . The VI trends were similar to that of 40 years and older participants in both the

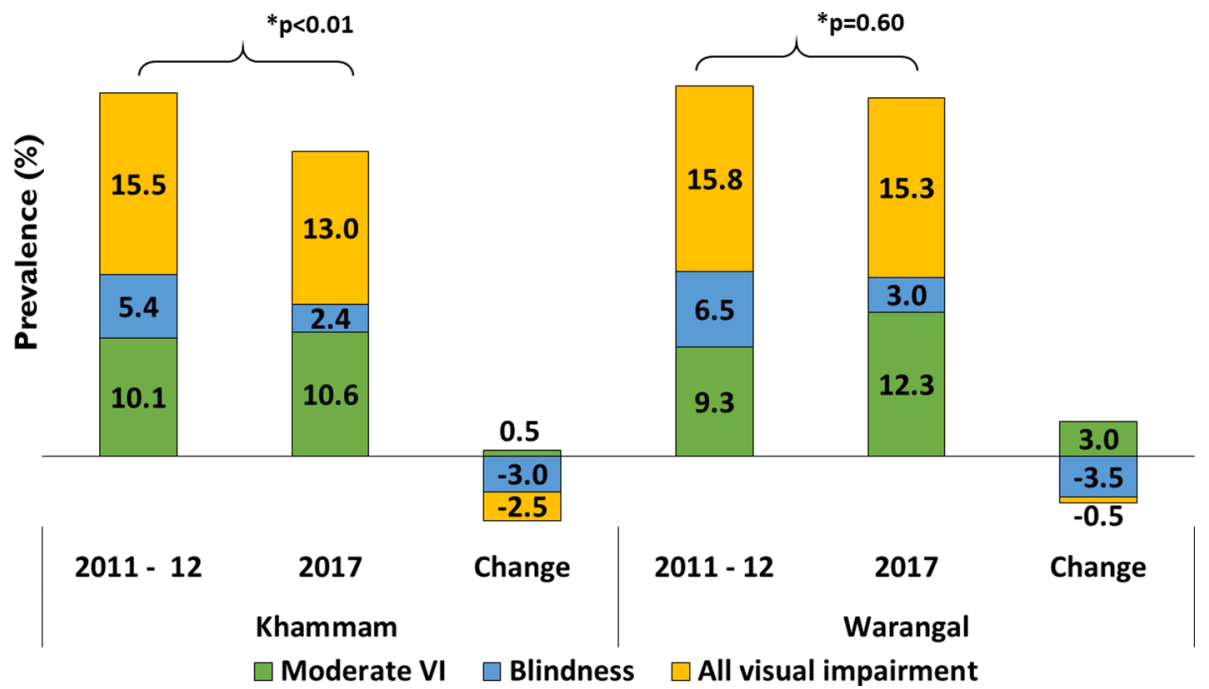

Figure 3 Categories of visual impairment (VI) in Khammam and Warangal districts: comparison between studies in $2011-2012$ and 2017. 


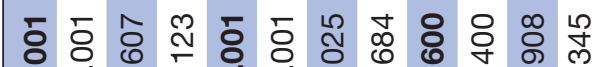
$a$
0

更

우

T⿱宀一

क्ष

กิ

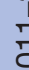

定

然

紊

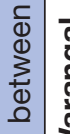

등

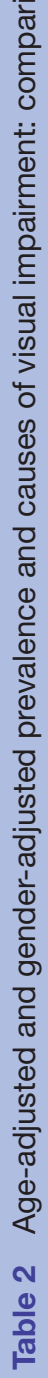

이

-

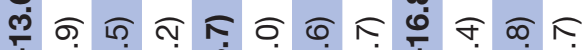
1 ம

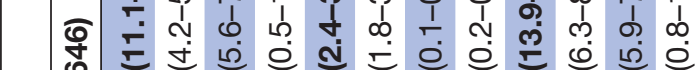

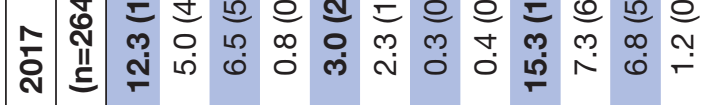

นึ้ว ชิ

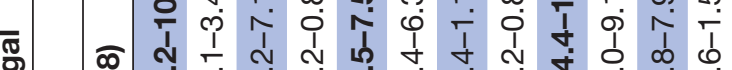

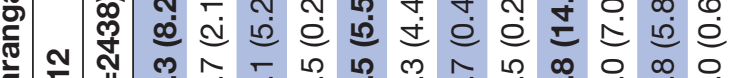

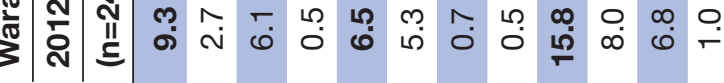

党 ๖ㅇ

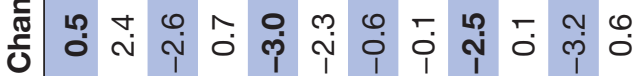

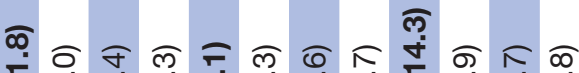

F ठำ

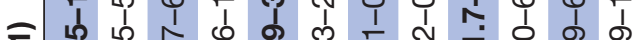

ᄀ

ก)
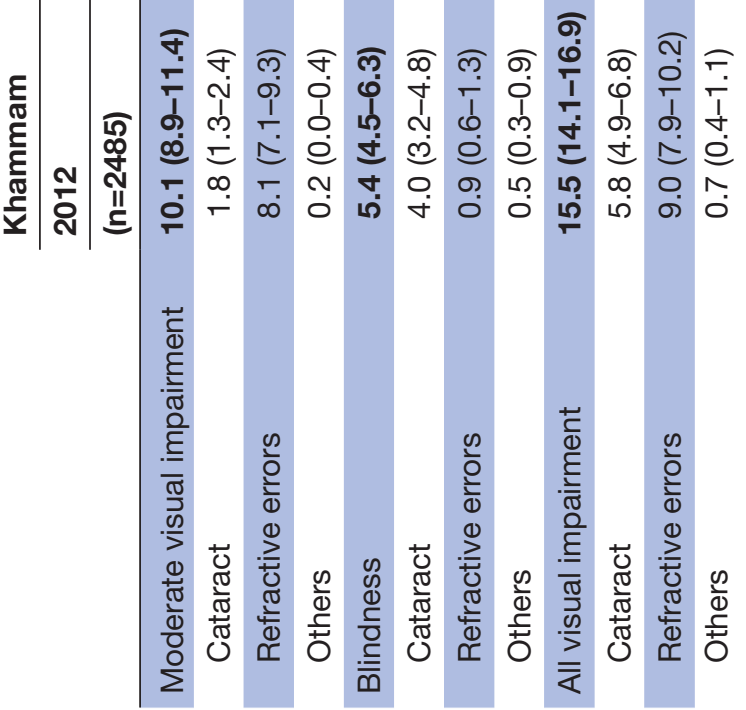

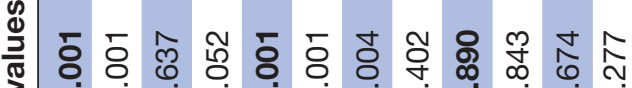

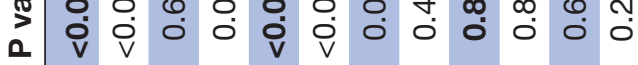

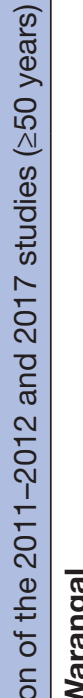

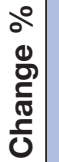

ᄃี

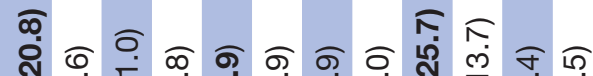

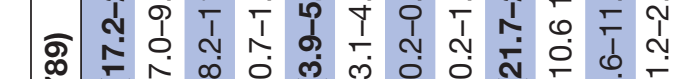

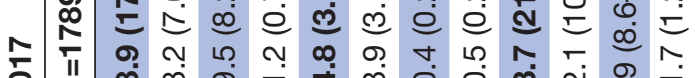

ㅇํ

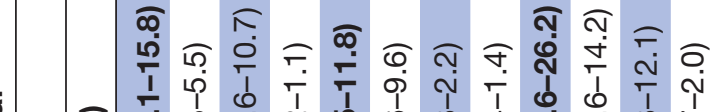

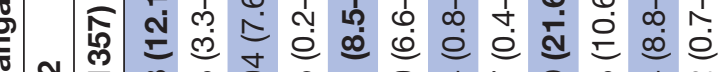

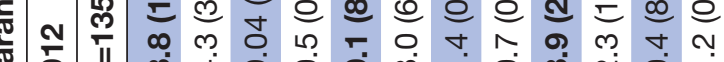

.

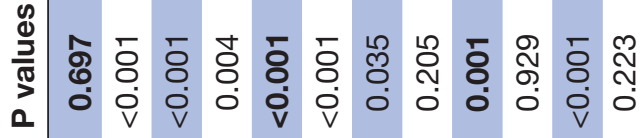

จำ

일

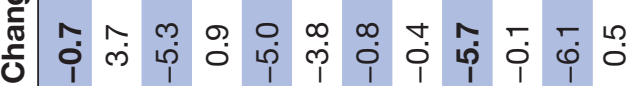

$\frac{\pi}{20}$

पू

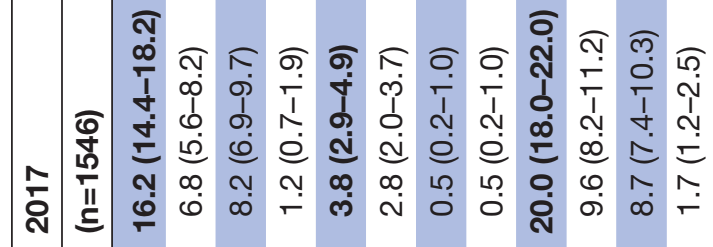

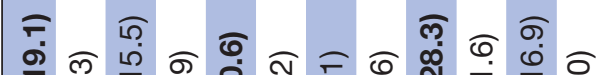

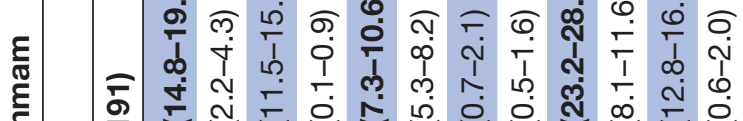

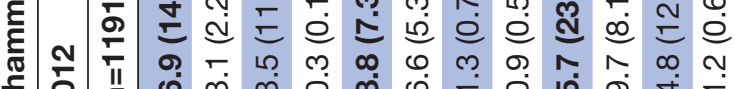

$\frac{1}{\frac{1}{2}}$

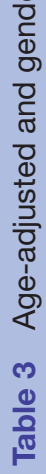

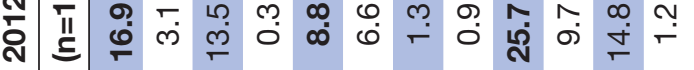

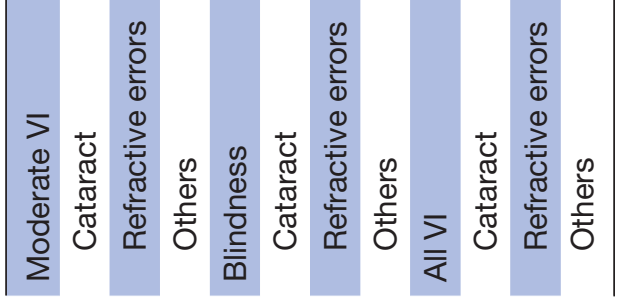

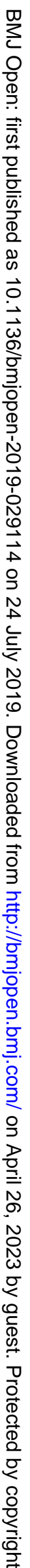


districts. In Khammam district, the overall prevalence of VI declined by $5.7 \%(p<0.001)$. There was no significant change in prevalence of MVI, but blindness declined by $5 \%(\mathrm{p}<0.001)$. In Warangal district, overall VI remained unchanged $(p=0.89)$. While MVI increased by $5.1 \%$ $(p=0.001)$, blindness declined by $5.3 \%(p<0.001)$.

\section{Cause-specific trends in the prevalence of $\mathrm{VI}$ in $\mathbf{5 0}$ years and older age groups}

In Khammam district, the prevalence of MVI caused due to cataract showed an increase of $3.7 \%(\mathrm{p}<0.001)$ but MVI caused due to refractive errors declined by $5.3 \%$ $(p<0.001)$. In Warangal district, the prevalence of MVI caused due to cataract increased from $4.3 \%$ to $8.2 \%$ $(p<0.001)$ whereas there were no significant changes in MVI caused due to refractive errors and other causes. Blindness caused due to cataract and refractive errors showed a significant decline by $4.1 \%(<0.001)$ and $1.0 \%$ $(\mathrm{p}=0.004)$, respectively (table 3$)$.

\section{DISCUSSION}

Two large population-based studies conducted 5 years apart in the same geographical locations in two large districts in the state of Telangana in India, with good response rates and identical protocols revealed a differential trend in prevalence and causes of VI. LVPEI established a secondary centre and 10 primary eye care centres (vision centres) after the 2011-2012 study in Khammam district. There was no direct intervention from LVPEI in Warangal district and it was left to the secular trends in service provision. There was a $2.5 \%$ decline in the prevalence of VI in Khammam while there was no significant change in the prevalence VI in Warangal between the 2011-2012 and 2017 studies. As VI is a combination of MVI and blindness, it implies that VI may remain constant though there are changes in the proportion of MVI and blindness. As the decline in the prevalence of blindness is similar in both the districts, the decline in overall VI is mainly driven by differential trends in the prevalence of MVI. The prevalence of MVI remained stable in Khammam but increased by $3 \%$ in Warangal.

Cataract and refractive errors are the major causes of VI in both districts. The trends in the prevalence of VI observed are largely due to changes in the prevalence of these two conditions. As cataract is the leading cause of blindness, the changes in availability and accessibility of cataract surgical services and cataract surgical rate (CSR) can explain the trends to a certain extent. We found a significant increase in the prevalence of cataract surgery in Khammam compared to Warangal. Cataract surgeries are considered as the top priority under the National Programme for Control of Blindness (NPCB) in India. ${ }^{20}$ The decline in blindness due to cataract is a healthy trend and suggests an improvement in cataract surgical services in both the districts. The CSR increased from 4090 in 2013-2014 to 6864 in 2016-2017 in Warangal and from 7086 in 2013-2014 to 8716 in 2016-2017 in Khammam district (Personal communication, Office of District Programme Manager, NPCB, Government of India). The increase in the prevalence of MVI caused due to cataract can be associated with the ageing population and also with the issues related to uptake of services by people with MVI caused due to cataract. Our earlier research has shown that the 'lack of felt need' is an important factor that determines the utilisation of eye care services among those with MVI. ${ }^{21}$ However, CSR is not an indicator of visual outcome after cataract surgery and hence the number of surgeries may not directly translate to a decline in the prevalence of VI caused due to cataract.

Refractive errors were another important cause of VI. Our results have shown a significant decline in the prevalence of MVI caused due to refractive errors in Khammam district. This differential trend can be attributed to better availability and uptake of refraction services in Khammam compared with that in Warangal. Also in Khammam, we found a significantly higher prevalence of spectacle use for distance vision. LVPEI has set up a comprehensive secondary eye care centre and a network of 10 primary eye care centres (Vision Centres) in Khammam district. ${ }^{22}$ These Vision Centres provide refraction and spectacles dispensing services as a part a comprehensive undilated eye examination to every patient. The number of LVPEI Vision Centres and other optical outlets that provide refraction services in Khammam, and the faster pace of the set-up in Khammam than in Warangal, may have led to this comparative overall decline in Khammam. Possibly, it could have positively impacted the trend in Khammam compared with that in Warangal.

It is acknowledged that the eye health-seeking behaviour for the uptake of refraction services might not have changed during the short period of 5-6 years. Besides, the cross-sectional nature of our study design limits the information available to understand all the possible reasons for these trends.

In our previous publications, we have reported a declining trend of VI in the Adilabad and Mahbubnagar districts in Telangana. ${ }^{23}{ }^{24}$ Though these earlier studies were conducted in the same geographical locations, the study protocols differed. In this paper, we report from studies using identical protocols repeated in the same geographical locations rendering results that are directly comparable. Though regional variations were evident in the recent global data on VI, a declining trend in the prevalence of VI was reported. ${ }^{1}$ Similarly, the national surveys conducted in India have also shown significant regional variations. However, the overall prevalence of VI across the country has remained similar over the years. ${ }^{725}$

Our study has revealed valuable insights on the trends in the prevalence of VI. As fluctuations in the number of service providers over time along with a measure of their contributions in these two districts are not readily available, these may have impacted the trends that lent themselves to measurement here. The data that we have presented on the trends in the prevalence of VI reflect on the eye health situation in these two districts. Our study 
can easily be used for planning district-specific strategies to address the burden of VI in future.

\section{Author affiliations}

${ }^{1}$ Allen Foster Community Eye Health Research Centre, Gullapalli Pratibha Rao International Centre for Advancement of Rural Eye care, L V Prasad Eye Institute, Hyderabad, Andhra Pradesh, India

${ }^{2}$ Brien Holden Institute of Optometry and Vision Science, L V Prasad Eye Institute, Hyderabad, Telangana, India

${ }^{3}$ WellcomeTrust / Department of Biotechnology India Alliance, L V Prasad Eye

Institute, Hyderabad, Telangana, India

${ }^{4}$ School of Optometry and Vision Science, University of South Wales, Sydney, NSW, Australia

Acknowledgements The authors thank the volunteers for their participation in the study. The authors also thank Guvvala Venkatesh, Buhyavarapu Sanjay Bhargav, Yellimalla Srikanth, Kolakaluri Praveen Kumar, Seelam Siva Nagaraju (vision technicians) for the assistance provided in data collection. The authors also thank Mr U Vijay Kumar (administrator) for providing logistic support for the study, Ratnakar Yellapragada for support in data management, Prof Jill Keeffe for her scientific inputs on earlier versions of this manuscript, and Ms Neha Hassija and Dr Shobha Mocherla for language inputs in earlier versions of our manuscript.

Contributors SM conceived the idea, designed and conducted the study, analysed the data and wrote the manuscript. SY, RC and JM assisted in data collection, clinical quality control and supervised the field activities. RCK and GNR reviewed the earlier version of the manuscript and provided intellectual inputs.

Funding Hyderabad Eye Research Foundation, India and Lions Clubs International Foundation (LCIF), SightFirst Research grant (SF 1943/UND).

Map disclaimer The depiction of boundaries on the map(s) in this article do not imply the expression of any opinion whatsoever on the part of BMJ (or any member of its group) concerning the legal status of any country, territory, jurisdiction or area or of its authorities. The map(s) are provided without any warranty of any kind, either express or implied.

Competing interests None declared.

Patient consent for publication Not required

Ethics approval Institutional Review Board (IRB), Hyderabad Eye Research Foundation, LVPEI.

Provenance and peer review Not commissioned; externally peer reviewed. Data sharing statement № additional data are available.

Open access This is an open access article distributed in accordance with the Creative Commons Attribution Non Commercial (CC BY-NC 4.0) license, which permits others to distribute, remix, adapt, build upon this work non-commercially, and license their derivative works on different terms, provided the original work is properly cited, appropriate credit is given, any changes made indicated, and the use is non-commercial. See: http://creativecommons.org/licenses/by-nc/4.0/.

\section{REFERENCES}

1. Bourne RRA, Flaxman SR, Braithwaite T, et al. Magnitude, temporal trends, and projections of the global prevalence of blindness and distance and near vision impairment: a systematic review and metaanalysis. Lancet Glob Health 2017;5:e888-97.

2. Flaxman SR, Bourne RRA, Resnikoff S, et al. Global causes of blindness and distance vision impairment 1990-2020: a systematic review and meta-analysis. Lancet Glob Health 2017;5:e1221-34.

3. Marmamula S, Khanna RC, Kunkunu E, et al. Population-based assessment of prevalence and causes of visual impairment in the state of Telangana, India: a cross-sectional study using the rapid assessment of visual impairment (RAVI) methodology. BMJ Open 2016;6:e012617.

4. Marmamula S, Madala SR, Rao GN. Rapid assessment of visual impairment (RAVI) in marine fishing communities in South India-study protocol and main findings. BMC Ophthalmol 2011;11:26.

5. Marmamula S, Narsaiah S, Shekhar K, et al. Visual impairment among weaving communities in Prakasam district in South India. PLoS One 2013;8:e55924.

6. Gupta N, Vashist P, Malhotra S, et al. Rapid assessment of visual impairment in urban population of Delhi, India. PLoS One 2015;10:e0124206.

7. Neena J, Rachel J, Praveen V, et al. Rapid assessment of avoidable blindness in India. PLoS One 2008;3:e2867.

8. Murthy GV, Vashist P, John N, et al. Prevelence and causes of visual impairment and blindness in older adults in an area of India with a high cataract surgical rate. Ophthalmic Epidemiol 2010;17:185-95.

9. WHO. Universal Eye Health: A global action plan 2014-2019. 2013:28.

10. Marmamula S, Keeffe JE, Rao GN. Rapid assessment methods in eye care: an overview. Indian J Ophthalmol 2012;60:416-22.

11. Kuper H, Polack S, Limburg H. Rapid assessment of avoidable blindness. Community Eye Health 2006;19:68-9.

12. Marmamula S, Khanna RC, Narsaiah S, et al. Prevalence of spectacles use in Andhra Pradesh, India: rapid assessment of visual impairment project. Clin Experiment Ophthalmol 2014;42:227-34.

13. Marmamula S, Madala SR, Rao GN. Prevalence of uncorrected refractive errors, presbyopia and spectacle coverage in marine fishing communities in south india: rapid assessment of visual impairment (RAVI) project. Ophthalmic Physiol Opt 2012;32:149-55.

14. Marmamula S, Narsaiah S, Shekhar K, et al. Presbyopia, spectacles use and spectacle correction coverage for near vision among cloth weaving communities in Prakasam district in South India. Ophthalmic Physiol Opt 2013;33:597-603.

15. Marmamula S, Narsaiah S, Shekhar K, et al. Visual impairment in the South Indian state of Andhra Pradesh: Andhra Pradesh - rapid assessment of visual impairment (AP-RAVI) project. PLoS One 2013;8:e70120.

16. Rao GN, Khanna RC, Athota SM, et al. Integrated model of primary and secondary eye care for underserved rural areas: the L V Prasad Eye Institute experience. Indian J Ophthalmol 2012;60:396-400.

17. Marmamula S, Khanna RC, Shekhar K, et al. Outcomes of Cataract Surgery in Urban and Rural Population in the South Indian State of Andhra Pradesh: rapid assessment of visual impairment (RAVI) project. PLoS One 2016;11:e0167708.

18. Marmamula S, Khanna RC, Narsaiah S, et al. Prevalence of spectacles use in Andhra Pradesh, India: rapid assessment of visual impairment project. Clin Exp Ophthalmol 2014;42:227-34.

19. Washington Group on Disability Statistics. Short set of disability questions. Secondary Short set of disability questions. http://www. washingtongroup-disability.com/washington-group-question-sets/ short-set-of-disability-questions.

20. Bhaduri G. National Programme for Control of Blindness--a review. Indian J Public Health 1997;41:25-30.

21. Marmamula S, Khanna RC, Shekhar K, et al. A population-based cross-sectional study of barriers to uptake of eye care services in South India: the Rapid Assessment of Visual Impairment (RAVI) project. BMJ Open 2014;4:e005125.

22. Rao GN. An infrastructure model for the implementation of VISION 2020: the right to sight. Can J Ophthalmol 2004;39:589-90.

23. Khanna RC, Marmamula S, Krishnaiah S, et al. Changing trends in the prevalence of blindness and visual impairment in a rural district of India: systematic observations over a decade. Indian J Ophthalmol 2012;60:492-7.

24. Marmamula S, Keeffe JE, Narsaiah S, et al. Changing trends in the prevalence of visual impairment, uncorrected refractive errors and use of spectacles in Mahbubnagar district in South India. Indian J Ophthalmol 2013;61:755-8.

25. Bachani D, Murthy GV, Gupta KS. Rapid assessment of cataract blindness in India. Indian J Public Health 2000;44:82-9. 